\title{
A Single Integrated ATM Card Model for Efficient Financial Transactions
}

\author{
Adekunle Adeyelu \\ Benue State University \\ Department of Mathematics \\ and Computer Science, Nigeria
}

\author{
Innocent Ogwuche \\ Benue State University \\ Department of Mathematics \\ and Computer Science, Nigeria
}

\author{
Tivlumun $\mathrm{Ge}$ \\ Benue State University \\ Department of Mathematics \\ and Computer Science, Nigeria
}

\begin{abstract}
In this work a model that integrates all the accounts statements and transactions of a client into a single Automated Teller Machine (ATM) access card was developed. This was with a view to address the challenges of the multiple cards carried by ATM card users operating accounts with different banks. The model harnessed the accounts of the customers using the Bank Verification Number (BVN), a unique identification code given to a customer holding at least one account with a bank. The algorithm for the model was developed and simulated using MATLAB 7.10. The results showed that the processing time and cost of maintenance for integrated card is less than that for multiple cards. The study concludes that the model will facilitate card safety, reduce the cost of issuing multiple cards by the banks and cost of maintenance of the card by the customers. Additional layer of security is also an advantage.
\end{abstract}

\section{General Terms}

Model, Algorithm, Security

\section{Keywords}

ATM, BVN.

\section{INTRODUCTION}

During the past decades, the banking industry has experienced increased innovation arising from information technology advances that have caused important changes in their products and business processes. These facilitated their functions of providing products and services to citizens and residents of host countries as well as being foundations of the payments systems and funds transfer between investors with surplus funds and capital seeking entities which have scarce funds [1]. For this sector, the internet marks the transition from the brick and mortar stage of banking to the branchless stage. Information Technology (IT) has moderated the constraints of time, space, and information access in world trade and commerce as a whole [2]. The growing popularity of Electronic Funds Transfer (EFT) for online bill payment, for instance, is paving the way for a paperless universe where cheques, stamps, envelopes, and paper bills will become obsolete [3][4]. In recent years, banks have made their services increasingly convenient through electronic banking which uses computers to carry out transfers of money. These forms include debit cards, electronic transfers, Mobile banking, Internet banking and ATM to mention a few [5].

The Automated Teller Machine (ATM), a computerized telecommunications device provides the clients of a financial institution with access to financial transactions in a public space without the need for a cashier, human clerk or bank teller.[6][7]. On most modern ATMs, the customer is identified by inserting a plastic ATM card with a magnetic stripe or a plastic smart card with a chip that contains a unique card number and some security information such as account number and expiration date. Using an ATM, customers can access their bank accounts in order to make cash withdrawals, credit card cash advances, and check their account balances as well as purchase prepaid cell phone credit and other financial transactions. Authentication is provided by the customer entering a Personal Identification Number (PIN), which when this is duly provided and validated, access and use is permitted. The machine was invented to provide mobile banking thus solving the problems of access to one's account from anywhere in the world where such network is available and accessible, provided the machine is in good shape and working properly. It provides ease to banking as it saves time energy and resources. In Nigeria, services presently obtainable from the ATM are withdrawal of cash, balance enquiry, changing of security PIN and purchase of prepaid cell phone credit, payment of electricity and satellite television subscription bills, inter and intra bank funds transfer just to mention a few. The benefits of the introduction of this system into the banking system are numerous. These include flexible and convenient accounts access by customers at any hour of the day, wider area of coverage of the banking services especially smaller population areas that the banks are not physically situated, efficient crowd control in banking halls, and reduction in expenses and risk of theft of bulk money as clients withdraw just the amount they need per time [5][6][10].

\section{LIMITATION OF RELATED WORKS}

The introduction of ATM in banking system with its enormous advantages came with obvious challenges which affect the customers. In Nigeria for example, banks issue one ATM card for each account, at most aggregate all the accounts of a client in one bank into one ATM card. Many clients have different types of accounts with different banks serving different purposes. This implies that a customer will have to own as many ATM cards as the number of banks he has accounts with. Having multiple cards could result in a number of challenges and limitations. These include loss and theft incidents involving loss or theft of ATM cards, fraudulent transactions as a result of using multiple cards either for online transactions or at POS resulting in huge monetary losses for consumers as well as financial institutions, confidential data such as card number, expiration date, and Card Verification Value (CVV) number are vulnerable to theft giving the opportunity for cyber hackers to open a new account in the name of the cardholder and run up their balances, missing or late payment penalties for the 
reason that multiple cards generate multiple bills to be paid on different due dates, with penalties or a payment of higher interest rates, and high costs of printing, shipping, processing, sticker activation, postage of multiple cards by financial institutions. This work attempts to tackle these problems by developing a model that will harness heterogeneous accounts and coordinate the transactions of a client using one ATM card on any machine. It adapts the mobile phone model which allows the use of multiple SIM cards in one mobile phone so that users need not to carry many mobile phones to access different networks. Here the user is expected to possess one ATM card which can be used to access and carry out transactions on any of his accounts.

\section{MATERIALS AND METHODS}

Investigations were conducted by direct observation which involved studying how the present ATM system works. Questionnaires were developed and administered to ATM card users to obtain their responses with respect to their experiences with using the system and suggestions on how it can be improved. The proposed system was modeled using UML diagrams and pseudocode algorithm and implemented using Java enterprise edition programming language and MySQL relational database manager. The performance of the model were measured by simulation using MATLAB 7.10.

\section{ANALYSIS OF THE MODEL}

The architecture of the ATM system is as shown in figure 1 . It consist of the ATM users, ATM machines, Central switching company and commercial banks. The ATM users are the customers requesting for services from their banks through the ATM. They can access and carry out transactions on their accounts from any ATM machine anytime anywhere within the geographical location specified by the financial institutions. The ATM machines provide the allowable services as requested by the card holder. The Central switching company is an organization or a networked group of organizations licensed to provide network connectivity services to the customers and banks via the ATM machines. Banks hold centralized data for individual customers on their databases. All transactions are carried out online on the Banks' databases. The accounts of a customer are harnessed together using the customer's Bank Verification Number $(\mathrm{BVN})$, a primary key stored among the information on the card. The software coordinates the user's accounts from same and/ or different banks and displays them for the requested transactions. By simply inserting the plastic card into the machine and entering the PIN/ fingerprint on the keypad or fingerprint scanner, the customer can access all the active accounts and carry out legitimate transactions on them. When a card holder inserts his card into the ATM machine the machine reads the BVN, expiry date and name of customer embossed on the front side of the card and compares it with the data stored on the re-writable magnetic strip looking for a "match " of information on both sides. If all the information matches, then all details of the active accounts of the client are retrieved and displayed for customer's choice of transaction. Each transaction on an account requires a PIN/ fingerprint for authentication. The algorithm for the model is as shown in figure 2 below.

The following time and cost parameters were identified as necessary in the overall analysis of the system.
i. $\quad \mathrm{T}_{\mathrm{C}}=$ time taken to read the card and get ready to request for Personal Identification number in seconds
ii. $\quad T_{\mathrm{P}}=$ time taken to read and confirm password (in seconds)
iii. $\quad \mathrm{T}_{\mathrm{T}}=$ time taken to carry out a transaction (in seconds)
iv. $\quad \mathrm{T}_{\mathrm{E}}=$ time taken to eject card and remove (in seconds)
v. $\quad \mathrm{T}_{\mathrm{A}}=$ time taken to insert new card (in seconds)
vi. $\mathrm{T}_{\mathrm{S}}=$ time taken to switch from one account to the other. (in microseconds)
vii. $\mathrm{N}=$ number of cards. This is equivalent to number of accounts.
viii. $\quad \mathrm{C}_{S}=$ cost of production of single card
ix. $\quad C_{R}=$ cost of renewal of a single card
x. $\quad \mathrm{C}_{\mathrm{P}}=$ cost of programming to a card
xi. $\quad \mathrm{T}_{\mathrm{M}}=$ response time for multiple cards operations
xii. $\quad \mathrm{T}_{\mathrm{O}}=$ response time for Single card operations

The ATM machine is expected to be effective and efficient. The performance parameters examined in this work are processing time and cost of maintenance. The two categories of operations were operating the ATM as a customer with $\mathrm{N}$ number of cards $\mathrm{N} \leq 10$ and operating it with a single card with $\mathrm{P} \leq 10$ accounts. The assumptions taken include:

i. $\quad$ Each account is attached to one ATM card, i.e. $\mathrm{N}=\mathrm{P}$

ii. The customer carries out one transaction at a time on an ATM card or account.

iii. Each transaction takes the same time.

iv. User enters the correct PIN.

v. Network connectivity is good at the time of access of the ATM machine.

vi. The difference in cost of production of integrated card and single card is significantly low.

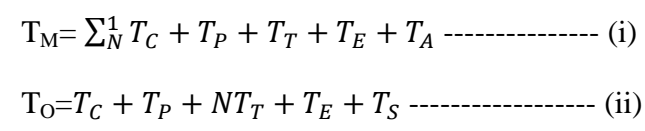

Total cost of maintenance of cards for multi-cards in a year $\mathrm{C}_{\mathrm{M}}=\mathrm{C}_{\mathrm{S}}+\mathrm{NC}_{\mathrm{R}}+\mathrm{C}_{\mathrm{P}}$------------- (iii)

Total cost of maintenance of card for single integrated card in a year $\mathrm{C}_{\mathrm{O}}=\mathrm{C}_{\mathrm{S}}+\mathrm{C}_{\mathrm{R}}+\mathrm{C}_{\mathrm{P}}$-------- (iv) 


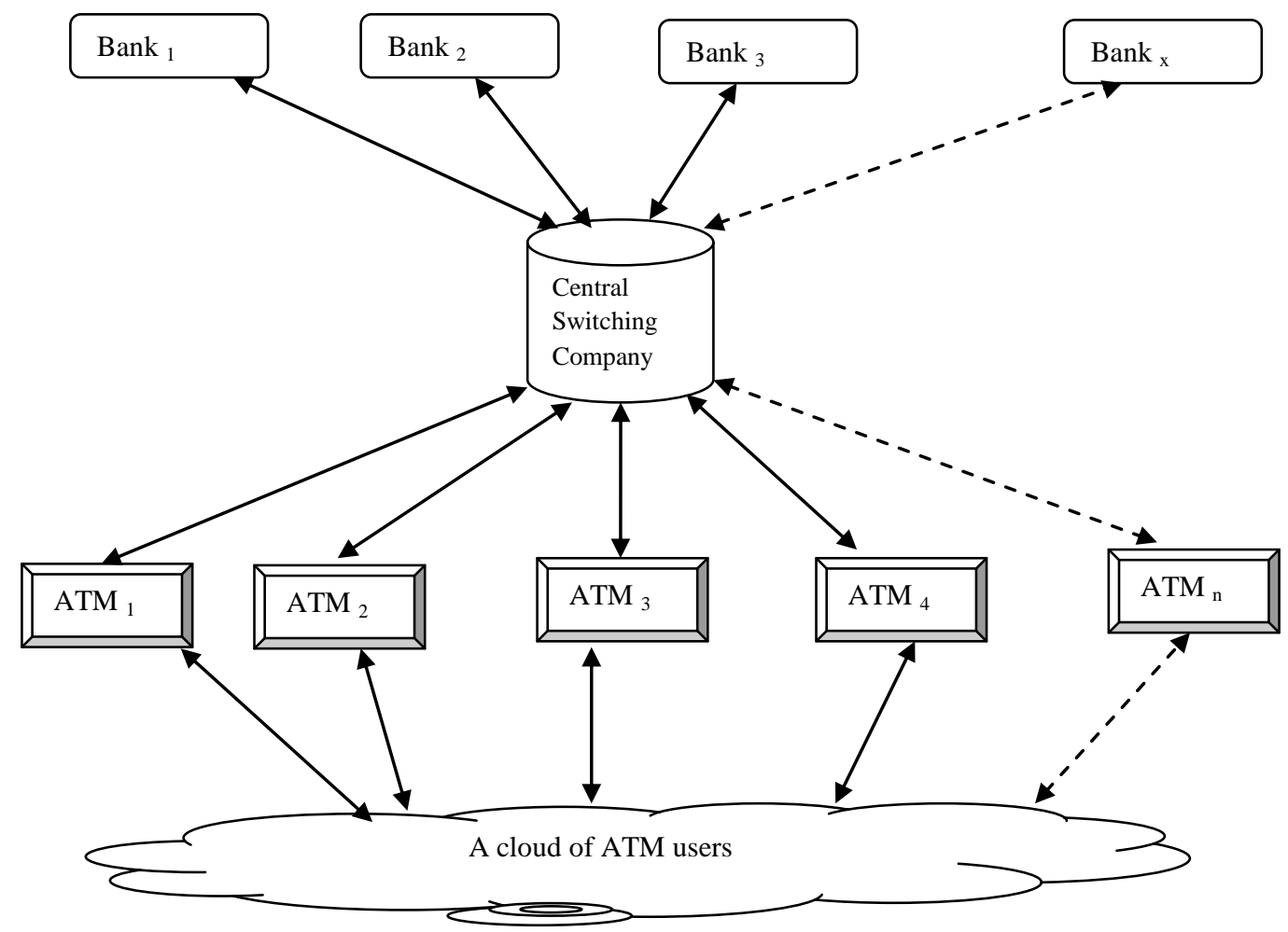

Fig 1: Architecture of the Single Card ATM System.

Input BVN: Unique Bank Verification number of a customer

ExpiryDate: Expiry Date of the Single ATM Card

CustomerName: Name of the Owner of the Card

PIN $(1, \ldots \ldots, N)$ : Personal Identification Number of Customer for different transactions

Output: result of successful transaction

1.1 Customer inserts card into the ATM machine and enters PIN(1)

1.2 If $(\mathrm{PN}(1)=$ CorrectPin $)$ then

1.3 $\quad$ read BVN, ExpiryDate, CustomerName;

1.4 Compare BVN, ExpiryDate, CustomerName with BVNSaved, ExpiryDateSaved, CustomerNameSaved) on Card

1.5 If match

1.13 Function Customer carry out transaction

1.14 ( while not CancelTransaction==TRUE or EndTransaction==TRUE

$1.15\{$ read PIN(x) for CurrentTransaction; 


\section{RESULTS AND DISCUSSION}

The model was simulated using MATLAB 7.10. The timing parameters were randomly generated using the linear multiplicative congruential pseudo random number generator. The response time for the two scenarios were plotted against $\mathrm{N}$ (Number of cards a customer possesses which is equivalent to number of accounts the customer has) as shown in Figure 3. The gradient of the graph were taken at four different quartile positions. The results showed that the gradient for the multiple card operation was constant at $20 \mathrm{~s} / \mathrm{N}$ at all the four quartile positions. This implied that the processing time per card is the same for that scenario. The results also showed that the gradient for single integrated card operation reduced linearly from the first quartile to the fourth quartile as $8.50 \mathrm{~s} / \mathrm{N}$, $6.50 \mathrm{~s} / \mathrm{N}, 4.67 \mathrm{~s} / \mathrm{N}$ and $4.0 \mathrm{~s} / \mathrm{N}$ respectively. This showed that the response time an individual experiences on the ATM reduces when using a single integrated card to access the ATM than when using each card to access each account for $\mathrm{N}$ number of cards.

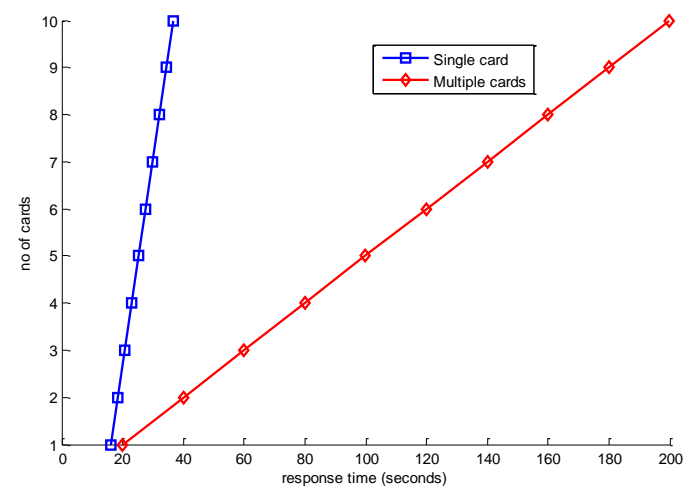

Figure 3: Graph of response times against number of cards/accounts for Multiple and Integrated Card Transactions.

Secondly the cost performance metric was mathematically analyzed. It showed that the total cost of maintenance of cards for multi-cards in a year $\mathrm{C}_{\mathrm{M}}=\mathrm{C}_{\mathrm{S}}+\mathrm{NC}_{\mathrm{R}}+\mathrm{C}_{\mathrm{P}}$, is more than total cost of maintenance of card for single integrated card in a year, $C_{O}=C_{S}+C_{R}+C_{P}$. i.e. $C_{M}>C_{O}$. Thus it is cheaper to maintain a single integrated card than multiple cards.

\section{CONCLUSION, RECOMMENDATION AND FUTURE WORKS}

The benefits of integrating multiple cards into a single card are enormous. These include significant card safety due to reduction in rate of loss and theft, reduced cost gained in issuing multiple cards by designated institutions, additional security due to a new security measure introduced into the system using a new PIN or fingerprint for the single card apart from the individual PIN numbers or fingerprints for each account. This new model is a solution that allows access everywhere anytime. It offers an inexpensive maintenance option for stress-free and secured transactions for banks and customers. The ease and consistency the single card option facilitated will encourage multiple accounts holders embrace it.
However, for this model to be functional, it is recommended that it should be made to be present everywhere. The existing infrastructure in the country therefore should therefore be upgraded. The organization providing the services such as issuing the ATM cards, and ATM machines would also have to upgrade their infrastructure (hardware and software) to meet the needs; though at an initial high cost. Government agency for banking and financial institutions should provide regulatory policies to force these institutions to adopt the proposed single card system.

Security of data is a major concern when data from heterogeneous institutions are integrated into a single card especially when the design of individual databases for each of these institutions from the onset did not consider integration in the future. Issus about loss of card, availability of financial data, and others should be looked into.

\section{REFERENCES}

[1] Agboola, A.A 2003 Information Technology, Bank Automation, and Attitude of Workers in Nigerian Banks in Journal of Social Sciences, Kamla-Raj Enterprises, Gali Bari Paharwali, India.

[2] Woherem, E. W. 2000. Information Technology in the Nigerian Banking Industry, Spectrum, Ibadan.

[3] Ogwu L.O. Oyebisi T.O., Ilori M.O. and Adagunodo E.R. 2000. Organizational Impact of Information Technology on Banking and Insurance Sector in Nigeria TECHNOVATION Vol. 20, No 12.

[4] Irechukwu, G. 2000. Enhancing the Performance of Banking Operations Through Appropriate Information Technology, In: Information Technology in Nigerian Banking Industry, Spectrum Books, Ibadan.

[5] Hillier, D. 2002. Money Transmission and the Payments Market, Financial World Publishing, Kent UK, ISBN 085297-643-7.

[6] Di Angeli, A., Coventry, L., \& Johnson, G. I. 2002. ATM's adoption in developing countries: Déjà vu or not? Advanced Technology and Research, Dundee, UK: NCR Financial Solutions Division.

[7] Batiz-Lazo, B., and Barrie, A. 2005. The business and technological history of automated teller machines in the UK, 1967-2005, a Primer. Conference Abstracts, 16-17th June. Queen Mary, University of London.

[8] Hayashi F., Sullivan R. and Weiner S.E 2003. A Guide to the ATM and Debit Card Industry, Payments System Research Department. Federal Reserve Bank of Kansas City, Kansas City, Missouri, USA.

[9] Darch, U., \& Caltabiano, N. J. 2004. Investigation of automatic teller machine banking in a sample of older adults. Australasian Journal on Ageing, 23(2), 100-103.

[10] Adetayo, J.O. Sanni, S.A. and Ilori M.O. 1999 The Impact of Information Technology on Product Marketing: A Case Study of Multinational Company in Nigeria' Technovation, Elsevier Science Ltd. 